\title{
DESENVOLVIMENTO DE UM SECADOR DE CESTO ROTATIVO PARA FOLHAS: APLICAÇÃO NA SECAGEM DE FOLHAS DE EUCALIPTO (Corymbia citriodora)
}

\author{
J. V. FREITAS ${ }^{1 *}$, M. C. FERREIRA ${ }^{1}$ \\ ${ }^{1}$ Universidade Federal de São Carlos, Programa de Pós-Graduação em Engenharia Química \\ *e-mail: julianapromad@gmail.com
}

\begin{abstract}
RESUMO
O objetivo deste trabalho é o desenvolvimento de um secador para a secagem de folhas, tipo rotativo, construído a fim de permitir uma boa mistura das folhas no processo, e assim garantir um produto final com umidade homogênea e de boa qualidade. O secador consiste de um cilindro construído de tela metálica perfurada, acoplado a um motor que permite a rotação em torno do seu eixo. $\mathrm{O}$ ar fornecido por um soprador é aquecido e alimentado através das paredes laterais, no sentido perpendicular ao eixo do cilindro. $\mathrm{Na}$ secagem das folhas, foi avaliada a reprodutibilidade dos dados, a influência da temperatura na cinética de secagem e a homogeneidade da secagem no cesto rotativo em relação à secagem em estufa comercial. Para a avaliação da qualidade do produto final, foi avaliada a influência da secagem no teor de óleo extraído e na concentração de citronelal presente no óleo. Os dados de cinética foram reprodutíveis e a temperatura teve forte influência na cinética de secagem das folhas. Os testes indicaram que o cesto rotativo proporciona a secagem uniforme das folhas se comparada à secagem em estufa, com umidade final média de 7,3 $\pm 0,3 \%$ para uma massa ideal de folhas $(50 \mathrm{~g})$. A secagem no secador rotativo não influenciou o teor de óleo essencial e houve redução da concentração de citronelal no óleo para os tratamentos de 50 e $60{ }^{\circ} \mathrm{C}$, mas não para 70 ${ }^{\circ} \mathrm{C}$.
\end{abstract}

\section{INTRODUÇÃO}

As plantas aromáticas possuem componentes que podem ser alterados pelo processo de secagem. Assim, devem-se tomar cuidados quanto à escolha do método adequado, a fim de adquirir um produto seco com as qualidades desejadas.

A escolha de um secador adequado depende de vários fatores envolvidos no processo. Keey (1978) sugeriu que os principais são: a forma de transferência de calor, a temperatura e pressão de operação e a forma que o material é manuseado dentro do secador. O tipo de secador a ser selecionado depende também da finalidade almejada ao produto final. Para as folhas, as aplicações finais visam em geral as indústrias alimentícia, de cosméticos e a farmacêutica.

A secagem de plantas deve ser realizada até atingir umidade na faixa de $8 \%$ a $12 \%$ b.u., conforme a espécie e a parte da planta (ROCHA, 2012). O uso de temperaturas muito altas pode provocar a perda de compostos voláteis, pois são altamente sensíveis, assim, para cada espécie há um limite de temperatura do ar, que varia conforme o tipo de secador a ser utilizado.

Muitas vezes, a secagem convectiva das folhas ocorre em secadores de leito fixo (como esteiras e bandejas) ou em estufas. Nestes secadores, cuidados com a espessura da camada de material, o uso de temperaturas adequadas e o tempo de revolvimento devem 
ser considerados, de forma a não favorecer a formação dos gradientes de temperatura e umidade do material ao longo do leito (CASTRO, 1991). Como exemplo, Lima (2013) realizou a secagem de folhas de manjericão em leito fixo e constatou que tanto na secagem em camada fina, como em camada espessa, houve formação de gradientes de umidade. A autora relatou que as folhas encolhem de forma significativa durante o processo, o que altera a estrutura dos leitos. Na secagem em camada espessa (para temperaturas de 30,45 e $60{ }^{\circ} \mathrm{C}$ ), Lima observou que os gradientes de temperatura foram mais intensos para $60{ }^{\circ} \mathrm{C}$, e a umidade das folhas localizadas no interior do pacote se manteve elevada em relação àquelas localizadas nas regiões próximas às paredes, já que o escoamento do ar ocorria preferencialmente nestas regiões.

A fim de minimizar estes gradientes de umidade, recomenda-se o revolvimento frequente do material, o que é pouco prático para a secagem de grandes quantidades. Outra alternativa, é o uso de configurações que permitam a movimentação do material, promovendo um contato uniforme entre as fases sólida e a fluida, como por exemplo, os secadores de leitos fluidizados, vibrofluidizados e tambores rotativos. Nestes secadores, a movimentação pode ser feita de maneira automatizada, possibilitando $\mathrm{o}$ processamento em maior escala.

Assim, o objetivo deste trabalho é o desenvolvimento de um secador que assegure a movimentação do material e proporcione uma secagem uniforme e um produto de boa qualidade e homogêneo.

O secador desenvolvido é para folhas em geral e foi baseado na configuração do secador de tambor rotativo. Como material de estudo foi escolhida a folha da espécie Corymbia citriodora, a qual é uma árvore de porte médio, e é facilmente identificada pelo forte cheiro do citronelal presente no óleo extraído de suas folhas (VITTI; BRITO,

2003). Esta espécie foi reclassificada por Hill e Johnson (1995), alterando de Eucalyptus para o gênero Corymbia, devido a características morfológicas e moleculares.

\section{MATERIAIS E MÉTODOS}

\subsection{Material}

As folhas foram colhidas no cerrado da Universidade Federal de São Carlos - São Carlos, as quais possuíam umidade inicial de $49,1 \pm 0,3 \%$.

Devido à grande variação de tamanho dependendo da sua posição nos galhos, foram descartadas as folhas de comprimentos menores que $10 \mathrm{~cm}$, mas procurando-se preservar a heterogeneidade que é peculiar de sua espécie. As folhas selecionadas para a secagem apresentaram comprimentos de $14,5 \pm 2,7 \mathrm{~cm}$.

\subsection{Equipamento}

A construção do secador tipo cesto rotativo foi baseada na configuração do secador de tambor rotativo, tendo em comum com este equipamento $\mathrm{o}$ formato $\mathrm{e} o$ movimento de rotação.

O secador construído consiste de um cesto cilíndrico (Figura 1) de $20 \mathrm{~cm}$ de diâmetro e $18 \mathrm{~cm}$ de comprimento. Um motor de 1/15 HP com sistema de redução para operar de 0 a 15 RPM, mostrado pelo ${ }^{\circ}$ (1), é acoplado à lateral esquerda do cesto, e permite a sua rotação em torno do seu eixo. Desta forma, as folhas podem se movimentar em seu interior durante a secagem. A velocidade de rotação pode ser ajustada por meio de um controlador da marca Diacti.

Figura 1 - Esquema do cesto rotativo

(1)

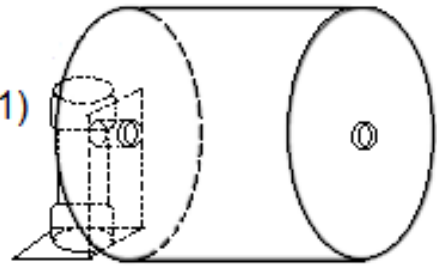

Fonte: Autor (2014). 
O material utilizado para a confecção do cesto é composto de 2 telas perfuradas de aço inoxidável, sendo uma tela de malha de 2 x 2 mm e uma tela de maior resistência mecânica, com orifícios de $2 \mathrm{~cm}$ de diâmetro, que confere a estrutura principal do cesto, como mostra a Figura 2.

Figura 2 - Imagem das telas perfuradas.

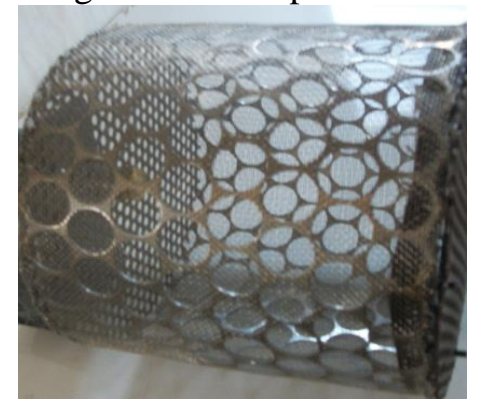

Fonte: Autor (2014).

As bases do cesto são feitas de telas de ferro perfuradas, de orifícios de $0,6 \mathrm{~cm}$ de diâmetro. Uma das bases é fixada por 4 parafusos, dispostos em distâncias iguais entre si. Esta base pode ser removida, o que permite que seja inserido e/ou retirado o material do seu interior. O cesto é inserido lateralmente em um duto de escoamento de ar, como mostra a Figura 3.

Figura 3 - Imagem do cesto inserido no duto de escoamento de ar em vista lateral direita.

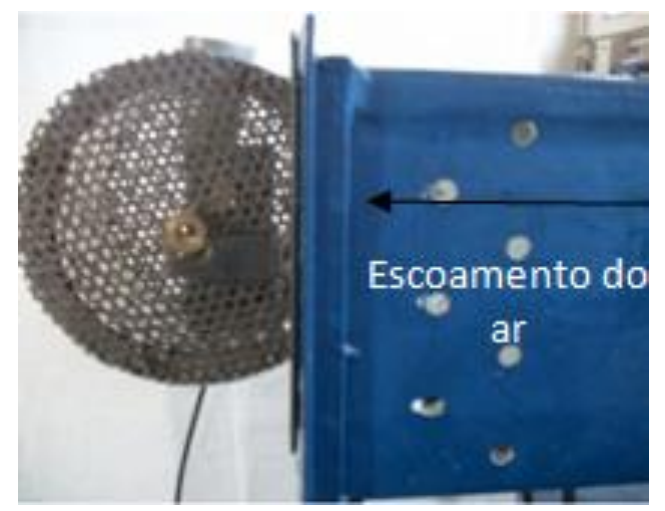

Fonte: Autor (2014).

$\mathrm{O}$ ar é alimentado a partir deste duto e atravessa as paredes perfuradas na direção perpendicular ao eixo longitudinal do cesto. A tubulação que direciona o ar alimentado no cesto tem dimensões de $20 \mathrm{~cm}$ de largura por $20 \mathrm{~cm}$ de altura. $\mathrm{O}$ ar é fornecido por um soprador axial Ibram (modelo VC 3560, 3469 RPM, 4 CV), e uma válvula gaveta permite o ajuste da vazão. A Figura 4 mostra a unidade de secagem com todos os seus componentes.

Figura 4 - Vista lateral da linha de fornecimento de ar e secador tipo cesto rotativo.

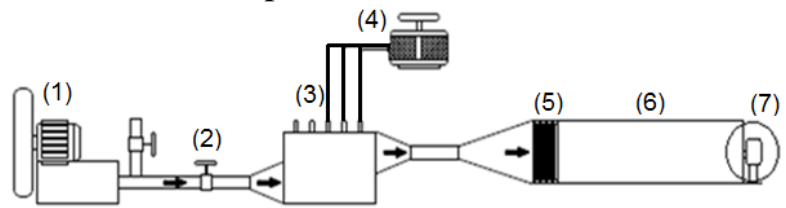

Fonte: Adaptado de Costa (2013).

Legenda: (1) Soprador, (2) Regulagem de vazão, (3) Aquecedor, (4) Variador de tensão, (5) Sistema de homogeneização do ar, (6) Duto de escoamento de ar e (7) Cesto.

$\mathrm{O}$ aquecimento do ar é feito por um conjunto de 3 resistências elétricas de $1000 \mathrm{~W}$ ligado em um variac da marca Varivolt, que permite ajustar a potência de saída, e assim, manter a temperatura do ar no valor desejado.

Como as folhas de eucalipto são longas, estas foram dispostas no interior do cesto com o comprimento no sentido do eixo do cilindro, o que permitiu melhor acomodação das folhas.

As condições de secagem podem ser alteradas variando-se: a temperatura do ar, a velocidade do ar e a velocidade de rotação do cesto. Como o secador é um equipamento novo e as condições de operação desconhecidas, a escolha dos valores utilizados na avaliação da secagem foi baseada em algumas referências de trabalhos anteriores. Também foram feitos alguns testes preliminares, de forma a avaliar possíveis condições de operação.

Para a velocidade do ar foi adotado o valor de $0,75 \mathrm{~m} / \mathrm{s}$, que é um valor intermediário entre os usados nos trabalhos 
sobre secagem de ervas e folhas medicinais (ERBAY; ICIER, 2009; KAYA; AYDIN, 2009).

Para a rotação do cesto foram consultados trabalhos desenvolvidos no tambor rotativo (PERAZZINI, 2011; TARHAN et al., 2010). Foi observado na literatura que para o tambor rotativo, as rotações são baixas, testou-se então, a menor rotação que o motor acoplado ao cesto permitia sem a necessidade de instalação de um redutor de velocidade, que era de 4 RPM, e adotou-se este valor para os procedimentos.

$\mathrm{O}$ range de 50 a $70{ }^{\circ} \mathrm{C}$ foi escolhido com base no trabalho de Braga (2002). Optou-se por utilizar temperaturas de 50, $60 \mathrm{e}$ $70{ }^{\circ} \mathrm{C}$ nas avaliações da secagem.

Para a escolha da carga de folhas no secador foram feitos alguns testes preliminares com as folhas in natura, observando-se as condições que forneciam uma boa movimentação do material no interior do cesto. Com base nestes ensaios, adotou-se $100 \mathrm{~g}$ como a carga máxima.

As medidas de temperatura e velocidade do ar, realizadas no duto de escoamento de ar (Figura 4), foram feitas com um anemômetro presente no Kit Trisense da Cole Parmer Instruments Company (modelo 37000-90).

Durante o processo, foi aferida a variação de massa das folhas retirando-as do cesto em intervalos definidos de tempo e pesando-as em uma balança semi-analítica Gehaka (BK 400, precisão de 0,001g) até se atingir a massa constante. Com os dados da massa em função do tempo foi calculada a umidade adimensional (MR) utilizando a equação:

$M R=\frac{X_{t}-X_{e q}}{X_{i}-X_{e q}}$

Onde X corresponde ao conteúdo de umidade médio (b.s.) e o subscrito $\mathrm{t}$ corresponde ao instante $\mathrm{t}$, i à umidade inicial e eq à umidade de equilíbrio "dinâmico", ou seja, a que foi obtida no final da secagem.

Avaliou-se então a reprodutibilidade dos dados, o efeito da temperatura na cinética de secagem das folhas e a homogeneidade da umidade final das folhas.

\subsection{Avaliação da homogeneidade da secagem}

Para testar a eficiência da homogeneidade da umidade final do conjunto de folhas na secagem em cesto rotativo, foram escolhidas algumas condições de secagem. Foi determinada a umidade final de folhas coletadas em 5 posições no interior do cesto, conforme indicado na Figura 5.

Figura 5 - Esquema de coleta de folhas no cesto

Fonte: Autor (2014).

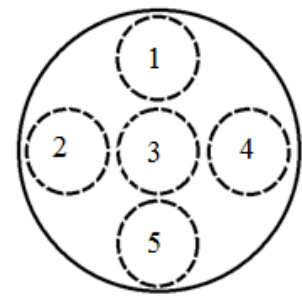

A fim de comparar a homogeneidade obtida na secagem realizada no cesto rotativo com um secador convencional, foram feitos ensaios de secagem em uma estufa de escala industrial (Figura 6).

Figura 6 - Estufa com circulação e renovação de ar MA 037.

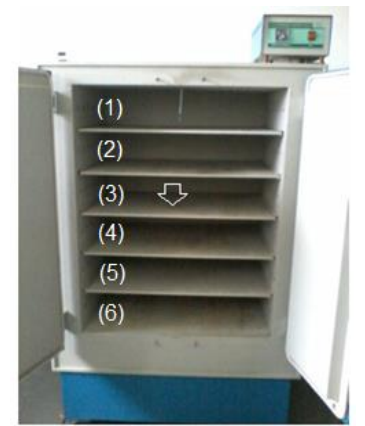

Fonte: Autor (2014).

A estufa, com renovação e circulação de ar tem capacidade de $0,42 \mathrm{~m}^{3}$, sua 
temperatura de operação máxima é $200{ }^{\circ} \mathrm{C}$, e contêm 6 prateleiras com dimensões $(80 \times 56$ $\mathrm{x} 15,5) \mathrm{cm}$.

Em estufas de grandes dimensões, a troca térmica com o ambiente é significativa, e isto afeta as correntes de convecção natural em seu interior, o que pode resultar em uma distribuição não uniforme de temperaturas, e consequentemente, em secagem não uniforme.

Para a secagem das folhas na estufa foram utilizadas 5 bandejas de tela perfurada com malha de $6 \times 6 \mathrm{~mm}$, com alturas de $5 \mathrm{~cm}$, e $25 \times 20 \mathrm{~cm}$ de comprimento e largura, respectivamente. A Figura 7 mostra as posições em que as bandejas ficaram localizadas na prateleira 3 e a vista lateral de uma bandeja, com indicação das posições em que as folhas foram coletadas.

Figura 7 - Esquema de localização das bandejas na prateleira 3 da estufa (a) e posições de coleta das folhas (b).

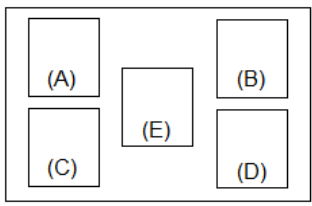

(a)

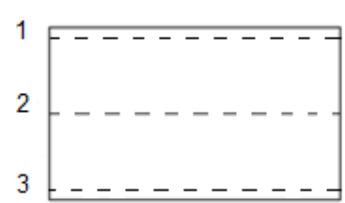

(b)
Fonte: Autor (2014).

Utilizou-se uma camada de $4 \mathrm{~cm}$ de folhas em cada bandeja, as quais foram dispostas nas posições indicadas na Figura 7(a). Ao final da secagem, foram retiradas amostras das posições 1,2 e 3 da bandeja (Figura 3.7(b)), que correspondem às alturas de $0 \mathrm{~cm}, 2 \mathrm{~cm}$ e $4 \mathrm{~cm}$ da camada de folhas, para a determinação de umidade final pelo método gravimétrico.

As umidades finais em base úmida $\left(\mathrm{U}_{\text {b.u. }}\right)$ foram calculadas com a equação 2:

$U_{\text {b.u. }}=\frac{M_{H 2 O}}{M_{t}}$
Onde $\mathrm{M}_{\mathrm{H} 2 \mathrm{O}}$ é a massa de água e $\mathrm{M}_{\mathrm{t}}$ é a massa total de folhas.

\subsection{Teor de óleo essencial}

O teor de óleo foi avaliado para as folhas secas, a fim de compará-lo com o teor obtido da folha in natura. A secagem das folhas foi feita em $2 \mathrm{~h}$ nas temperaturas de 50 , 60 e $70{ }^{\circ} \mathrm{C}$, a fim de avaliar a influência da temperatura de secagem. $O$ processo de extração de óleo foi realizado pelo método Clevenger. O teor de óleo foi calculado em base seca (ou seja, considerando a massa de folhas isenta de umidade) a partir da equação:

$$
R_{\text {b.s. }}=\frac{M_{o}}{M_{s}} \cdot 100
$$

Onde $\mathrm{M}_{\mathrm{O}}$ é a massa de óleo e Ms a massa seca de folhas (massa seca + massa de óleo).

\subsection{Concentração de citronelal no óleo}

Foi realizada a análise do citronelal presente no óleo essencial em cromatógrafo a gás (GC-17 $)$ acoplado a um espectrômetro de massas (modelo QP 5050), da Shimadzu, utilizando o metanol como solvente, a fim de comparar as concentrações de citronelal presente no óleo obtido para as folhas secas em relação às concentrações obtidas para a folha in natura. Os testes foram realizados no Laboratório de Cromatografia da USP de São Carlos.

\section{RESULTADOS E DISCUSSÃO}

Foi realizada uma verificação prévia da uniformidade da temperatura e velocidade do ar alimentado no secador.

As medidas foram feitas em 6 diferentes posições no duto de escoamento de ar (Figura 4), com distâncias iguais entre si na direção perpendicular ao escoamento. Como não foi possível realizar as medidas no próprio cesto, 
admitiu-se que essas condições se mantêm no interior do secador.

A temperatura apresentou variação máxima de $2,3{ }^{\circ} \mathrm{C}$, e a velocidade do ar de $0,11 \mathrm{~m} / \mathrm{s}$, indicando boa uniformidade do escoamento, devido à pequena variação entre as medidas.

Uma dificuldade observada na secagem de folhas é a obtenção de dados reprodutíveis, já que as amostras não são idênticas devido à variabilidade de tamanhos, formato e composição dos materiais biológicos. Assim, foi avaliada a reprodutibilidade dos dados e os resultados são mostrados na Figura 8.

Figura 8 - MR em função do tempo para $50 \mathrm{~g}$

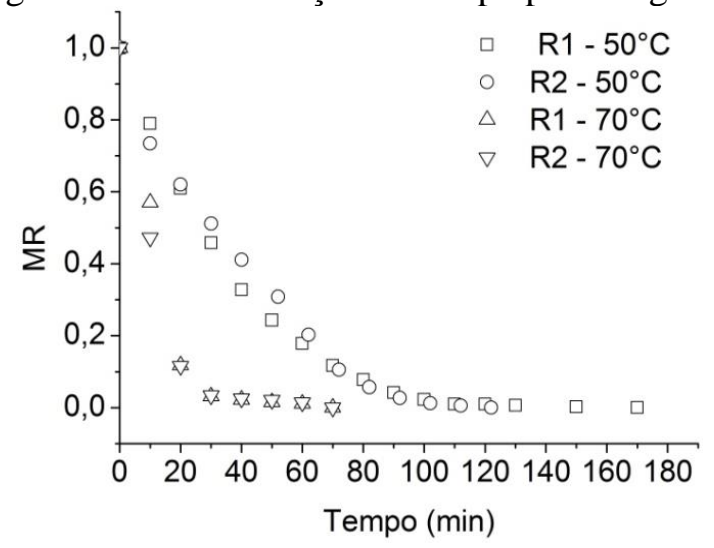

Fonte: Autor (2014).

Nota-se que para os 2 tratamentos de secagem, as curvas de cinética foram reprodutíveis. Os máximos desvios padrões obtidos para os valores da umidade adimensional (MR) ficaram em torno de 0,03 e o $\mathrm{R}^{2}$ referente à correlação das repetições foram de 0,9868 e 0,9918 para 50 e $70{ }^{\circ} \mathrm{C}$, respectivamente. Sendo assim, os desvios podem ser desprezados.

A Figura 8 permite também uma análise da influência da temperatura no processo. Nota-se que a temperatura teve forte influência na retirada de umidade e diminuiu de forma significativa o tempo de secagem. Em $70{ }^{\circ} \mathrm{C}$, a redução no tempo de secagem é aproximadamente $56 \%$ em relação à temperatura de $50{ }^{\circ} \mathrm{C}$. Nos primeiros 30 minutos de secagem a $70{ }^{\circ} \mathrm{C}$, a umidade adimensional caiu para um valor próximo de 0,1 . Comportamento similar foi relatado no trabalho de Mochi (2005), na secagem de folhas de Eucalyptus camaldulensis em leito fixo, utilizando temperaturas de 35 a $70{ }^{\circ} \mathrm{C}$, com velocidade de $0,6 \mathrm{~m} / \mathrm{s}$. A autora verificou que a maior parte da umidade foi retirada após 30 minutos de secagem para temperaturas superiores a $50{ }^{\circ} \mathrm{C}$. A forte dependência da temperatura na secagem de folhas também foi observado por Lima (2013) na secagem de folhas de manjericão.

Posteriormente foi avaliada a uniformidade final das folhas secas no secador tipo cesto rotativo. Testou-se então a massa de $100 \mathrm{~g}$ de folhas em $2 \mathrm{~h}$ de secagem. As umidades finais obtidas para $100 \mathrm{~g}$ de folhas estão apresentadas na Figura 9, em que $\mathrm{R} 1, \mathrm{R} 2$ e R3 correspondem às repetições dos ensaios.

Figura 9 - Umidades finais (b.u.) para 100 g após $2 \mathrm{~h}$ de secagem

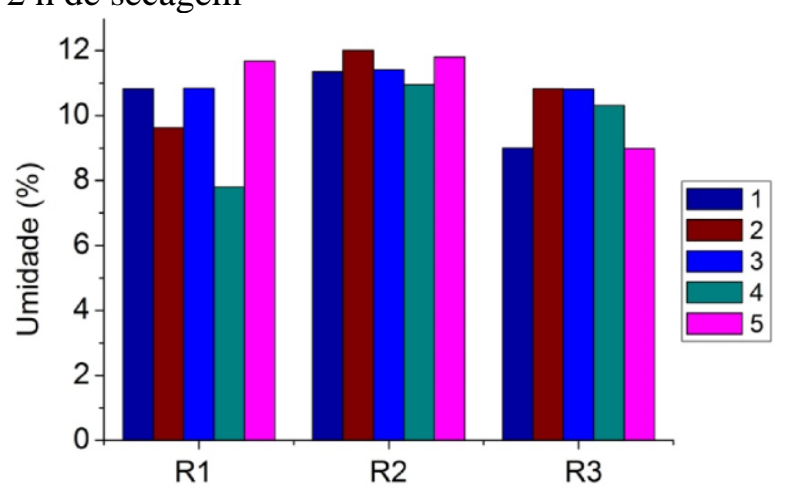

Umidades referentes às amostras retiradas das posições 1, 2, 3, 4 e 5 (Figura 5)

Fonte: Autor (2014).

Nota-se que para R1, as umidades nas diferentes posições tiveram variações mais significativas entre si, com diferenças de até 4\%. Para as amostras R2 e R3, os desvios foram menores, em torno de 1,2 e $2 \%$, respectivamente.

Durante o processo observou-se que as folhas ficam rígidas e retorcidas, e o conjunto 
aumentou de volume durante a secagem. A determinação da densidade bulk das folhas de eucalipto resultou em valores de $0,14 \pm 0,02$ $\mathrm{g} / \mathrm{cm}^{3}$ para as folhas in natura, e de $0,020 \pm 0,001 \mathrm{~g} / \mathrm{cm}^{3}$ para as folhas secas. Esta variação corresponde a um aumento de volume de cerca de $300 \%$ para uma mesma massa de material.

De acordo com BICALHO et al. (2010), a fração de material adequada deve estar entre 10 e $15 \%$ do volume dos secadores rotativos. Calculando o volume de folhas de eucalipto em relação ao volume do cesto, $100 \mathrm{~g}$ de folhas in natura representam a fração de $13 \%$ de volume de material no cesto e ao final da secagem o percentual de volume foi de $44 \%$.

Para a massa de $100 \mathrm{~g}$, as folhas tiveram boa movimentação no interior do cesto apenas no início da secagem, com movimento similar ao de cascateamento. Devido ao enrijecimento e ao aumento de volume, após um tempo de secagem, o conjunto de folhas passou a se comportar como um leito fixo giratório no interior do secador, o que prejudicou a movimentação das folhas, e consequentemente, o contato sólido-fluido.

Verifica-se na Figura 9 que as diferenças entre as umidades não foram reprodutíveis entre as repetições. Isto se deve ao fato de a amostra se comportar como um leito fixo, cuja estrutura não pode ser reproduzida entre diferentes ensaios. Esta variação de $4 \%$ na umidade entre as posições não pode ser considerada desprezível, contudo, é justificada, já que $100 \mathrm{~g}$ de folhas não se mostrou uma quantidade ideal para ser inserida no secador, visto que a movimentação das folhas não foi boa.

Avaliou-se então o grau de homogeneidade na secagem de $50 \mathrm{~g}$ de folhas, realizada durante $1,5 \mathrm{~h}$ na temperatura de 70 ${ }^{\circ} \mathrm{C}$. Esta quantidade $(50 \mathrm{~g})$ representa a fração de $6,5 \%$ de volume de material in natura no cesto e ao final da secagem o percentual de volume é de $22 \%$. As umidades estão dispostas na Figura 10.
Figura 10 - Umidades finais (b.u.) para $50 \mathrm{~g}$ após $1,5 \mathrm{~h}$ de secagem

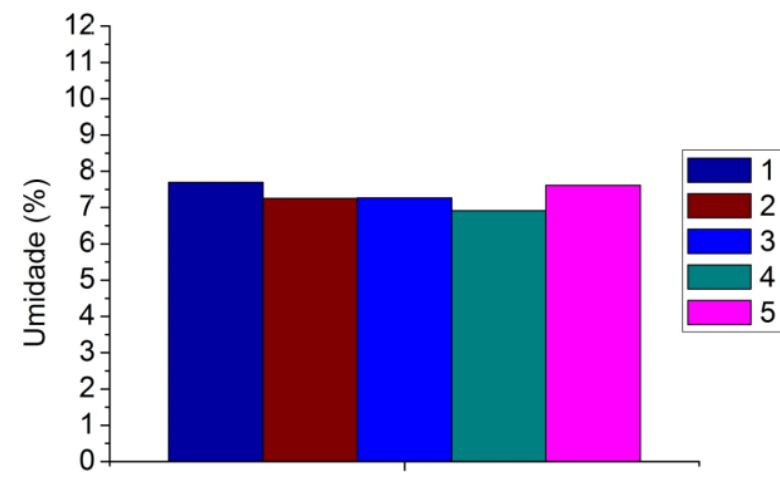

Umidades referentes às amostras retiradas das posições 1, 2, 3, 4 e 5 (Figura 5)

Fonte: Autor (2014).

Nota-se que as umidades ficaram entre 6,9 e $7,7 \%$, apresentando uma variação muito pequena $(0,8 \%)$, tendo como média entre as medidas de $7,3 \pm 0,3 \%$ (b.u.). Para massa de $50 \mathrm{~g}$ houve boa movimentação das folhas em todo o processo e o contato entre o ar e o material foi uniforme. $\mathrm{O}$ padrão de escoamento das folhas foi similar ao do cascateamento (característico de tambores rotativos), do início ao final do processo.

Considerando o volume total do cesto, a quantidade de folhas necessária para preenchê-lo totalmente é de 720 g e o ideal seria utilizar a capacidade máxima possível para a secagem das folhas. Como foi constatado que o conjunto de folhas aumenta de volume durante o processo, a escolha da quantidade de folhas ficou limitada por esta característica. Então, foram escolhidas as quantidades que apresentaram comportamentos distintos de escoamento, sendo estas de 100 e $50 \mathrm{~g}$ para a avaliação da homogeneidade da umidade final.

Com o objetivo de ter dados comparativos para avaliar a eficiência do secador desenvolvido em termos de uniformidade da secagem, foi realizada a secagem na estufa industrial, fixando o tempo de secagem em $2 \mathrm{~h}$, na temperatura de $70{ }^{\circ} \mathrm{C}$, e sem nenhum revolvimento do material 
durante a secagem. As folhas foram secas em bandejas de tela perfurada, com altura da camada de $4 \mathrm{~cm}$. Foram retiradas amostras de 3 alturas da camada de folhas na bandeja, sendo estas de 0,2 e $4 \mathrm{~cm}$. As umidades obtidas nas diferentes bandejas e posições de cada bandeja estão mostradas na Figura 11.

Figura 11- Umidades (b.u.) obtidas em diferentes posições para a estufa industrial após $2 \mathrm{~h}$ de secagem.

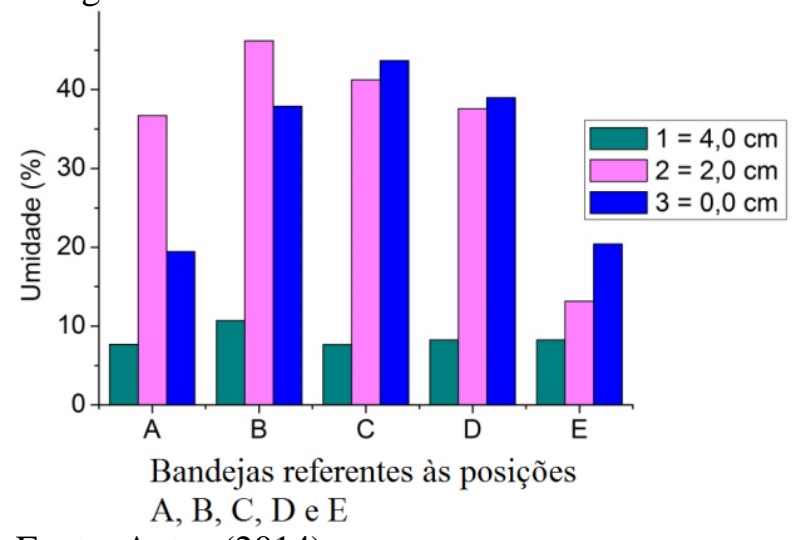

Fonte: Autor (2014).

Nota-se que, devido à ausência de revolvimento, as umidades obtidas ficaram muito elevadas para as folhas localizadas nas alturas 2 e 3 das bandejas (partes mais internas), com umidades próximas da umidade inicial, exceto para a bandeja (E) que ficou localizada no centro da prateleira, onde as umidades ficaram mais próximas, embora ainda sejam bem diferentes entre si.

A bandeja (E) ficou localizada no centro da prateleira, o que pode ter favorecido condições de secagem mais uniformes e maior temperatura do ar.

Na Figura 12 podem ser visualizadas as folhas após as $2 \mathrm{~h}$ de secagem em 2 posições na altura da bandeja (D), onde $\mathrm{a}=4 \mathrm{~cm} \mathrm{e} \mathrm{b}=$ $2 \mathrm{~cm}$.

Observa-se que as folhas localizadas na extremidade superior ficaram mais secas e mantiveram a coloração esverdeada, mas ao retirar a primeira camada de material, verifica-se que as folhas localizadas na parte mais interna da bandeja ficaram úmidas e escurecidas, comprometendo a qualidade final do produto. Estes resultados evidenciam a importância do revolvimento do material na secagem em bandejas, a fim de melhorar o contato sólido-fluido e garantir uma secagem uniforme.

Figura 12 - Imagem das folhas localizadas na altura 1 (a) e na altura 2 da bandeja (b).

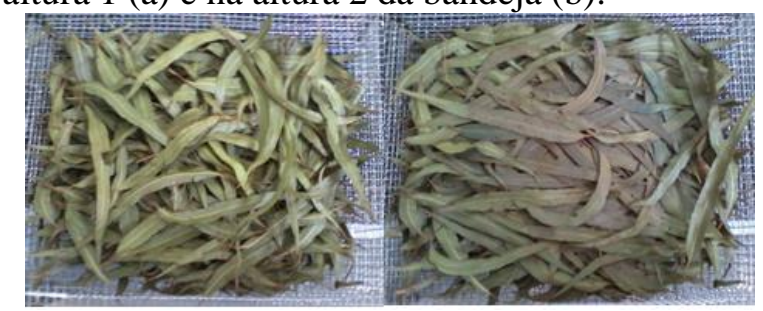

Fonte: Autor (2014).

\subsection{Avaliação do teor de óleo essencial em relação à folha in natura}

Os teores de óleo obtidos para os tratamentos de secagem nas temperaturas de 50, 60 e $70{ }^{\circ} \mathrm{C}$ estão mostrados na Figura 13, onde foi realizado o teste de Tukey a $95 \%$ de confiança. Para as mesmas letras os tratamentos não diferem estatisticamente entre si.

Figura 13 - Teor de óleo essencial (b.s.) para os diferentes tratamentos.

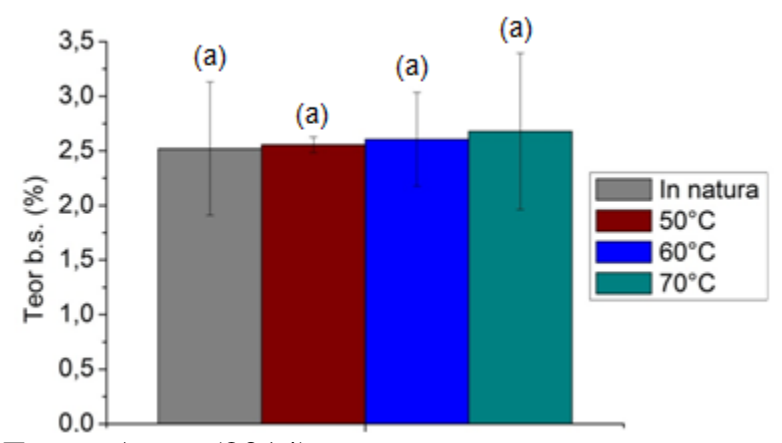

Fonte: Autor (2014).

Nota-se que os teores obtidos para as folhas secas em diferentes temperaturas não mudaram estatisticamente entre si, e nem em relação aos teores obtidos para a folha in natura, sendo a média total de $2,5 \pm 0,4 \%$ (b.s). Assim, a temperatura do ar de secagem não teve influência sobre a produção de óleo. 
Observa-se que os desvios padrões foram elevados, e isto pode ser explicado pelo fato de que foram realizadas coletas de folhas em 2 dias diferentes para os procedimentos experimentais. Sabe-se que a composição pode variar em função do dia da colheita e também porque foram utilizadas árvores diferentes para as coletas.

Braga (2002) realizou a secagem das folhas de Corymbia citriodora, utilizando o leito fixo em temperaturas de 30 a $60{ }^{\circ} \mathrm{C}$, e verificou que, para temperaturas superiores à $50{ }^{\circ} \mathrm{C}$, o teor de óleo (b.s.) decresceu. Como os métodos de secagem utilizados foram diferentes, maiores investigações seriam necessárias para esclarecer esta diferença nos comportamentos.

\subsection{Concentração de citronelal no óleo}

Foi avaliada a concentração de citronelal das folhas secas, para comparar com a concentração obtida para a folha in natura. A Figura 14 mostra os resultados da concentração do citronelal e as datas que foram realizadas as extrações e as secagens das folhas para os respectivos tratamentos.

Figura 14 - Concentração do citronelal $(\mathrm{g} / \mathrm{ml})$ no óleo extraído das folhas secas.

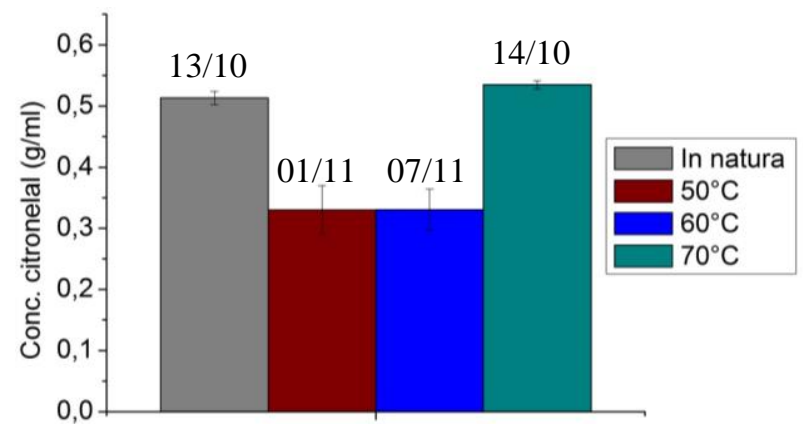

Fonte: Autor (2014).

Nota-se que as concentrações obtidas para as folhas secas nas temperaturas de 70 ${ }^{\circ} \mathrm{C}$, de 0,530 $\pm 0,006 \mathrm{~g} / \mathrm{ml}$, ficaram bem próximas da concentração obtida para a folha

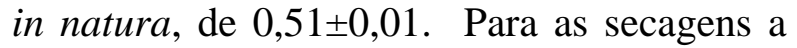
50 e $60{ }^{\circ} \mathrm{C}$, as concentrações de citronelal mostraram uma diferença significativa em relação à folha in natura, sendo de $0,33 \pm 0,04$ e $0,33 \pm 0,03 \mathrm{~g} / \mathrm{mL}$, respectivamente. Os percentuais obtidos para a folha in natura e para $70^{\circ} \mathrm{C}$ estão próximos aos encontrados na literatura que variam de 65 a $85 \%$ (VITTI E BRITO, 2003).

A redução no teor de citronelal nas temperaturas de 50 e $60{ }^{\circ} \mathrm{C}$ não era esperada, visto que a deterioração na secagem está geralmente associada com o aumento da temperatura. A perda de citronelal pode ter ocorrido, pelo fato das folhas terem sido coletadas e armazenadas antes das extrações. Para que fosse usado um único lote de folhas nos ensaios de extração, as folhas in natura foram coletadas no dia 13/10 e armazenadas em freezer, e as secagens e extrações foram realizadas de acordo com as datas mostradas na Figura 14.

Uma das hipóteses, é que como o teor de óleo não foi alterado pela secagem, é possível que o armazenamento tenha alterado a concentração de citronelal presente nas folhas, ou porque o tempo foi longo ou porque as condições não foram adequadas para a preservação deste constituinte.

Outra possibilidade, é que na temperatura de $70{ }^{\circ} \mathrm{C}$ a secagem tenha destruído as estruturas das células que retêm maior quantidade de citronelal, favorecendo a extração do óleo contido nas partes mais difíceis. Desta forma, o citronelal detectado no óleo extraído nas folhas in natura seria proveniente da fração de óleo mais "livre", cuja extração é mais fácil. Por outro lado, esta fração do óleo também está sujeita a maiores perdas por volatilização durante a secagem. Assim, a redução no teor de citronelal observado nas temperaturas de 50 e $60{ }^{\circ} \mathrm{C}$ poderia ser justificada pela volatilização, sendo que a $70{ }^{\circ} \mathrm{C}$ a perda de citronelal por volatilização teria sido compensada pelo componente obtido a partir do óleo contido nas estruturas mais internas, que ficaram acessíveis pela secagem a temperatura mais alta. 
A repetição dos testes e análises mais aprofundadas seriam necessárias para compreender a razão destes resultados.

\section{CONCLUSÕES} concluir:

A partir dos resultados obtidos pode-se

- O secador tipo cesto rotativo mostrouse adequado para a secagem de folhas de eucalipto, permitindo a redução de umidade em valores considerados adequados para armazenamento, sem alteração significativa no teor de óleo das folhas;

- O equipamento possibilita a secagem com boa reprodutibilidade de resultados e para as condições investigadas, a temperatura do ar teve forte influência no processo;

- Selecionando-se condições adequadas foi possível obter um produto homogêneo, com diferenças máximas de $0,8 \%$ na umidade das folhas. O desempenho do cesto rotativo, em termos de homogeneidade, foi superior ao da estufa industrial;

- Foi constatado que, para fornecer uma boa mistura e contato efetivo entre as fases, a carga máxima alimentada de folhas in natura não deve ultrapassar $10 \%$ do volume do cesto;

- A secagem não alterou o teor de óleo e houve redução das concentrações de citronelal nas folhas secas a 50 e $60{ }^{\circ} \mathrm{C}$, mas não para $70{ }^{\circ} \mathrm{C}$.

\section{REFERÊNCIAS}

BRAGA, N. de P. Influencia da secagem no rendimento e na composição do óleo essencial das folhas de Eucalyptus citriodora. 151 f. Dissertação (Mestrado) Curso de Engenharia Química, Área de Concentração em Engenharia de Processos, Unicamp, Campinas, 2002.

BICALHO, I. C. et al.. Estudo experimental e de simulação da fluidodinâmica em secadores rotatórios com cascateamento. FEQ-UFU, Uberlândia, 2010.

CASTRO, L. H. de Efeito do despolpamento, em secador de leito fixo sob alta temperatura no consumo de energia e na qualidade do café (Coffea arabica L.). $71 \mathrm{f}$. Tese (Doutorado) - Curso de Engenharia .Agrícola, UFV, Viçosa, 1991.

COSTA, A. B. S. Secagem convectiva de folhas de hortelã: análise baseada no ajuste de correlações empíricas, superfícies de respostas e redes neurais. $109 \mathrm{f}$. Dissertação (Mestrado) - Curso de Engenharia Química, UFSCar, São Carlos, 2013.

HILL, K.D.; JOHNSON, L.A.S. Sistematic studies in eucalyptus. A revision of the bloodwoods, genus Corymbia (Myrtaceae). Telopea, v.6, p. 173-505, 1995.

KEEY, R. B. Introduction to Industrial Drying Operations, 1 ed, Pergamon Press, New York, 1978.

LIMA, R. A. de B. Análise da secagem convectiva de folhas de Manjericão (Ocimum basilicum L.) 169 f. Tese (Doutorado) - Curso de Engenharia Química, UFSCar, São Carlos, 2013.

ROCHA, R. P. da. Avaliação do e da composição do óleo essencial de Cymbopogon citratus e Thymus vulgaris submetidos a processos de secagem e armazenamento. $176 \mathrm{f}$. Tese (Doutorado) Curso de Engenharia Agrícola, UFV, Viçosa, 2011.

VITTI, A. M. S.; BRITO, J. O. Óleo essencial de eucalipto. Documentos Florestais, n. 17, 2003. 